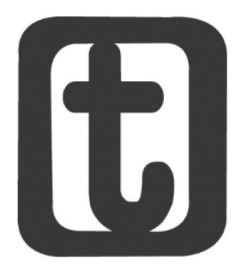

\title{
DESAFIOS DA PESQUISA NA FORMAÇÃO PROFISSIONAL DO ASSISTENTE SOCIAL: UM OLHAR A PARTIR DA EXPERIÊNCIA DO CURSO “ABEPSS-ITINERANTE”
}

\author{
CHALLENGES OF RESEARCH IN PROFESSIONAL \\ FORMATION OF THE SOCIAL WORKER: A LOOK FROM \\ THE EXPERIENCE OF “ABEPSS ITINERANTE" COURSE
}

\section{Ana Paula Mauriel' Olegna de Souza Guedes ${ }^{2}$}

\section{RESUMO}

O presente artigo tem como objetivo evidenciar os desafios mais significativos à pesquisa na formação profissional a partir da análise dos relatos dos participantes dos cursos da ABEPSS Itinerante das regionais Leste e Sul I da ABEPSS. Para tratar do tema proposto, o artigo será desenvolvido em duas partes. Na primeira, serão apresentados aspectos que caracterizam as dificuldades, os avanços e os limites da transversalidade da pesquisa nos cursos de Serviço Social. Busca-se relatar, nesta análise, as interpretações desses participantes acerca da concepção de pesquisa presente das Diretrizes Curriculares e de como buscam configurá-la operacionalmente nos seus respectivos currículos. Na segunda parte, o texto aponta os principais desafios e impasses que

1 Assistente Social pela UFRJ (1993), mestre em Serviço Social pela UFRJ (2000), Doutora em Ciências Sociais pela UNICAMP (2008). Professora da Escola de Serviço Social da Universidade Federal Fluminense, professora do Mestrado em Serviço Social e Desenvolvimento Regional da Universidade Federal Fluminense, Coordenadora do Grupo de Pesquisa sobre Política Social e Desenvolvimento (GPODE). E-mail: apmauriel@gmail.com

2 Doutora em Serviço Social, docente do programa de Graduação em Serviço Social e de Pós-Graduação em Serviço Social e Política Social da Universidade Estadual de Londrina, bolsista produtividade da Fundação Araucária: Apoio e Desenvolvimento Científico e Tecnológico do Paraná. E-mail: olegnasg@gmail.com 
acometem a construção da transversalidade da pesquisa na formação profissional na atual conjuntura.

Palavras-chave: Pesquisa. Formação profissional. Diretrizes curriculares.

\section{ABSTRACT}

The article aims to highlight the most significant challenges for research in professional formation from the analysis of the participants' reports of the ABEPSS Itinerant courses of ABEPSS regionals East and South I. To address the theme, the article will be developed in two parts. The first will present aspects that characterize the difficulties, progress and limits of transversality of research in Social Service courses. The text seeks to report, in this analysis, the understanding shown by the participants about the research design of Curriculum Guidelines and about how to configure it operationally in their respective curricula. Then, the text addresses the main challenges and dilemmas that affect the construction of transversality of research in professional formation in the current conjuncture.

Keywords: Research. Professional formation. Curriculum guidelines.

Submetido em 29/03/2013

Aceito em 09/06/2013

\section{INTRODUÇÃO}

Considerando os desafios para consolidação das diretrizes curriculares da ABEPSS diante do contexto da contrarreforma do ensino superior no Brasil (LIMA, 2008)3), este artigo tem como objetivos fornecer elementos para compreensão do papel da pesquisa na formação profissional, tendo com matéria-prima, a experiência de coordenação do curso de aperfeiçoamento "Diretrizes Curriculares e o Projeto de Formação Profissional de Serviço Social" (ABEPSS Itinerante) nas regionais Leste e Sul I'4.

3 "A contrarreforma da educação superior brasileira está pautada em dois eixos centrais: a diversificação das instituições de ensino superior e dos cursos e a diversificação das suas fontes de financiamento, em consonância com a política dos organismos internacionais - especialmente o Banco Mundial, a UNESCO e a OMC. Para os países da periferia do sistema capitalista. [...], essa política está direcionada ao fortalecimento da ação dos setores privados e para o acesso de segmentos populacionais pauperizados da população, sob a aparência de uma política inclusiva". (LIMA, 2008: 19)

40 curso foi realizado em todas as regionais da ABEPSS, com organizações diferenciadas conforme realidade de cada região, mas obedeceu ao mesmo programa, com a finalidade de cumprir os objetivos, o conteúdo e os 
Entendida como uma atribuição profissional que se localiza tanto no âmbito acadêmico - na graduação e na pós-graduação quanto parte constitutiva do exercício profissional do assistente social, que tem como orientação ética um processo de formação permanente para qualificação dos serviços prestados à sociedade, a concepção de pesquisa que orienta o debate do Serviço Social é resultado, sobretudo, de avanços da crítica ao conservadorismo, que se explicitam no perfil profissional presente nas diretrizes curriculares vigentes desde 1996, as quais conformam um dos pilares do projeto ético-político profissional (ABESS/ CEDEPSS, 1995).

A pesquisa no Serviço Social destaca-se como preponderante, sobretudo, para a análise de determinações sócio-históricas, tais como conjunturas políticas, econômicas e sociais que redesenham, redefinem e desafiam a agenda das políticas sociais, substratos basilares para as requisições das ações profissionais dos assistentes sociais.

A atitude investigativa, fundada, sobretudo, nas grandes áreas das ciências sociais e humanas, revela-se necessária para um profissional que tem seu espaço sócio-ocupacional dado, direta ou indiretamente, por expressões da questão social. Contudo, diante da heterogeneidade de perspectivas metodológicas nessas áreas do conhecimento, sustenta-se, no espaço da formação e da atuação profissional dos assistentes sociais, a necessária recorrência uma perspectiva teórico-metodológica que permita, sobretudo, a apreensão crítica dos processos sociais numa perspectiva de totalidade.

procedimentos de avaliação previstos no projeto e que estão descritos no material bibliográfico, disponibilizado sobre o título ABEPSS-ITINERANTE. Na regional Leste, foram organizadas três turmas: em Belo Horizonte (na sede do CRESS-BH) e Uberaba (na Escola de Serviço Social da UFTM), ambas no período de 13 a 16/06/12 (I etapa) e de 28 a 30/06/12 (II etapa), cujos facilitadores do módulo de pesquisa foram Ana Paula Mauriel (UFF) e Sheila Backx (UFRJ). A turma do Rio de Janeiro ocorreu na UFF Niterói no período de 26 a 29/09/12 (I etapa) e 18 a 20/10/12 (Il etapa), e o facilitador do módulo foi Gustavo Repetti (UFRJ). Na região Sul I, também foram três turmas, organizadas da seguinte forma: Londrina (PR), no período de 30/05/12 a 02/06/12 (I Etapa), facilitadora Sheila Backx (UFRJ); em Florianópolis (SC), nos períodos de 30/05/12 a 02/06/12 (I Etapa) e 14/06/12 a 16/06/12 (II Etapa), facilitadora Dúnia Comerlatto (Unichapecó); em Porto Alegre (RS), nos períodos de 22/06 a 30/06 (I Etapa) e nos dias 03/04 e 10/08/2012 (II Etapa), facilitador Tiago Martinelli (Unipampa). 
Essa perspectiva, necessária para a direção política construída por esta categoria profissional, consolidada, sobretudo, em seu projeto ético-político, traz uma série de desafios que vão desde a precariedade na formação profissional dos assistentes sociais, muitas vezes dadas por condições materiais nas quais elas se consolidam, até as armadilhas da alienação presente no cotidiano institucional dos profissionais.

Por isso, uma das exigências postas nas Diretrizes Curriculares de 1996, que orientam os cursos de Serviço Social, é para que as disciplinas que compõem o currículo mínimo desses cursos sejam direcionadas à formação de um profissional dotado de formação intelectual e cultural generalista crítica, competente em sua área de desempenho, com capacidade de inserção criativa e propositiva, no conjunto das relações sociais e no mercado de trabalho. Profissional comprometido com os valores e princípios norteadores do Código de Ética do Assistente Social de 1993.

Para refletir sobre esses desafios, o módulo destinado à pesquisa, nos Cursos de Aperfeiçoamento "ABEPSS-ITINERANTE”, orientou-se por objetivos que pretendiam refletir sobre a pesquisa na formação profissional do Serviço Social, a partir das condições de implantação das Diretrizes Curriculares de 1996. Para isso, fez-se necessário abordar a concepção, a importância e a análise crítica da pesquisa nessas diretrizes, nas quais ela se destaca, sobretudo, como eixo estruturante da organização curricular, haja vista que esta se orienta, entre outros princípios pelo:

- Rigoroso trato teórico, histórico e metodológico da realidade social e do Serviço Social, que possibilite a compreensão dos problemas e desafios com os quais o profissional se defronta no universo da produção e reprodução da vida social;

- Adoção de uma teoria social crítica que possibilite a apreensão da totalidade social em suas dimensões de universalidade, particularidade e singularidade;

- Estabelecimento das dimensões investigativa e interpretativa como princípios formativos e condição central da formação profissional e da relação teoria e realidade. 
Diante disso, foi proposto aos participantes do curso ${ }^{5}$ - supervisores de estágio, discentes e docentes vinculados a diferentes unidades de formação acadêmica públicas e privadas, universidades e faculdades - que, no final do módulo, contribuíssem para a construção de uma análise crítica sobre a pesquisa na formação profissional, por meio da identificação, em suas respectivas unidades de formação acadêmicas, de aspectos considerados necessários para materialização da pesquisa como componente essencial para a formação profissional qualificada. Esse exercício analítico, construído por esses participantes, permitiu-nos elencar aspectos relevantes a serem socializados para consolidar conquistas e enfrentar lacunas que dificultam a materialização na pesquisa na formação profissional do assistente social. É nessa direção que se segue o relato ora apresentado. Contudo, não identificaremos essas Unidades de Formação Acadêmica, neste artigo, para garantia do anonimato, por questões éticas.

A primeira parte do texto aponta o entendimento ilustrado pelos participantes acerca da concepção de pesquisa presente nas Diretrizes Curriculares e mostra como buscam configurar operacionalmente a pesquisa em seus respectivos currículos. A partir desses aspectos, o texto evidencia alguns dos principais desafios e impasses que acometem à construção da transversalidade da pesquisa na formação profissional, na atual conjuntura.

\section{EM BUSCA DA CONSTRUÇÃO DA TRANSVERSALIDADE DA PESQUISA NOS CURRÍCULOS}

Observa-se, nos relatos e avaliações dos participantes do curso, que há clareza, entre os membros das equipes das diferentes unidades de ensino, com relação à formação profissional na direção crítica indicada pelas Diretrizes Curriculares de 1996, voltadas à formação de um profissional com capacidade crítico-analítica necessária para responder às demandas do cotidiano profissional, como expressões de particularidades, mas que não

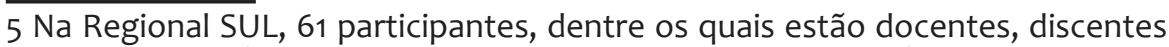
de pós-graduação que atuam como docentes e que ainda não ingressaram na carreira acadêmica e supervisores de estágio. Na Regional LESTE, 123 inscritos, desses 72 docentes, 14 estudantes de pós, 28 supervisores de campo, 11 representantes das comissões de formação dos CRESS Rio de Janeiro e Minas Gerais. 
se destacam da universalidade constitutiva da dinâmica da realidade. Tal capacidade é necessária para elaboração criativa de estratégias de intervenção comprometidas com as proposições ético-políticas do projeto profissional do Serviço Social.

Ressalta-se a clareza, entre esses participantes, com relação ao grau de abrangência da pesquisa em Serviço Social, tal como proposta nas Diretrizes Curriculares de 1996: "Concepção, elaboração e realização de projetos de pesquisa” (ABEPSS, 1996), bem como compreensão de sua natureza, quantitativa e qualitativa, e de seus procedimentos. Vincula-se às exigências postas por essa definição a necessária articulação entre ensino, pesquisa e extensão, com vistas a assegurar um processo de formação, no qual os profissionais sejam capazes de ultrapassar os muros da teorização, do pragmatismo, da ausência de relação entre teoria e prática e que se ancore na direção da consolidação do projeto ético-político em construção nesta categoria profissional.

Para consolidar a articulação entre essas três modalidades de projetos, sugere-se o necessário diálogo entre graduação e pós-graduação. Dentre as formas de viabilizá-lo, cita-se a inserção de discentes de diferentes níveis de formação (graduação e pós-graduação) em grupos de pesquisa; o empenho em ofertar, nos cursos pós-graduação, disciplinas voltadas à pesquisa e ao método, acessíveis aos discentes desses cursos que atuam como docentes nos cursos graduação de Serviço Social em diferentes Unidades de Formação Acadêmicas (UFA). Sugere-se, também, a necessária articulação entre os diferentes núcleos de estudos e pesquisa existentes nas unidades de ensino e aponta-se, como uma das dificuldades para concretizá-la, a redução do quadro docente; haja vista que o envolvimento em atividades diversas e excesso de carga horária didática incide, entre outros fatores, no isolamento dos docentes em suas pesquisas, o que coíbe iniciativas direcionadas à interação entre tais atividades.

Ainda na perspectiva de consolidar essa articulação, sugere-se que a construção de projetos de ensino, pesquisa e extensão vinculem-se às linhas de pesquisa dos programas de graduação e pós-graduação; o que facilita os discentes na escolha de projetos nos quais possam envolver-se como pesquisadores, além 
de ser importante para construção do processo investigativo. Entende-se que contribui para materialidade desse processo a construção de uma política de fomento às bolsas de iniciação científica e ao próprio desenvolvimento da pesquisa, a qual, muitas vezes, é desenvolvida com ausência de recursos.

Outros espaços indicados para fortalecer e fomentar a indissociabilidade entre esses projetos são os sócio-ocupacionais, que se tornam mais presentes nas universidades, através de estratégias como os fóruns de supervisores. Ou, sobretudo, em faculdades particulares, nas quais não há política que fomente a construção desses projetos, a realização de projetos pontuais, com temas específicos em parceria com órgãos públicos. Dentre as particulares, $12 \%$ de seus representantes afirmaram que, em suas faculdades, há projetos de extensão, ainda que de forma incipiente, com parceiras vinculadas a campos de estágios.

Assegurar essa indissociabilidade é, também, ter como direção a necessária articulação entre as aulas ministradas nas disciplinas que compõem a grade curricular nos cursos de Serviço Social e atividades desenvolvidas nos projetos de pesquisa e extensão, ainda que as condições materiais e políticas, dentre outras mediações que constituem a materialidade do ensino superior, apontem para o produtivismo ${ }^{6}$ e redução de quadro docente, de forma a enfraquecer tal indissociabilidade. Criar condições, ainda que rudimentares, para estimular os discentes a relacionar conteúdos ministrados em sala de aula com exercícios de pesquisa e extensão, é uma conquista a ser trilhada.

Com relação à efetiva materialização dessa indissociabilidade, a grande maioria dos representantes das escolas que participaram desse curso ${ }^{7}$ aponta dificuldades para assegurá-la e destaca-a como algo que ainda não tem materialidade em suas

6 Termo que vem sendo utilizado no debate sobre Educação Superior no contexto contemporâneo para sintetizar a tendência de intensificação do trabalho docente aliada à alienação, relações de trabalho competitivas entre si, resultantes dos processos de contrarreforma do Estado e da Educação Superior. Para maiores detalhes, consultar SGUISSARDI e SILVA JUNIOR, 2009.

7 Na Regional SUL, participaram representantes de 20 Unidades de Formação Acadêmicas. Na Regional LESTE, participaram representantes de 27 Unidades de Formação Acadêmicas, além de 8 instituições que são campos de estágio. 
unidades de ensino. Dentre as dificuldades apresentadas, cita-se desde a "pouca tradição acadêmica" entre o corpo docente, o que o leva a priorizar os projetos de extensão e ensino em relação aos de pesquisa, até a política das respectivas unidades de ensino; como também composição de equipes de docentes contratados como horistas e alunos trabalhadores. Concorre para superar tais dificuldades a participação em Editais de Fundações Estatuais de Apoio à Pesquisa Científica e Tecnológica, mas estes são insuficientes para superar a ausência de recursos para o investimento, sobretudo, em projetos de pesquisa.

\section{A PESQUISA NAS DIFERENTES UNIDADES DE ENSINO: TRANSVERSALIDADE E DIMENSÃO INVESTIGATIVA}

Ancorados nas diretrizes curriculares, há, nessas unidades, a preocupação do corpo docente em situar a pesquisa para além de uma disciplina específica, vinculando-a às dimensões técnico-operativa, teórico-metodológica e ético-política simultaneamente. Diante disso, em alguns currículos dessas unidades, tal disciplina situa-se no núcleo de trabalho profissional, sob a justificativa de que é necessária para desenvolver habilidades de investigação e conhecimento da realidade e dos elementos constitutivos da prática profissional do assistente social.

Para além de uma disciplina específica ou necessária às exigências da construção do Trabalho de Conclusão de Curso, situam a pesquisa como vinculada ao estímulo da postura investigativa dos discentes, necessária na intervenção profissional do assistente social e para formação de pesquisadores capazes de produção científica a ser socializada dentro e para além da nossa categoria profissional. Valorizam-se, nessa direção, os diferentes espaços e registros de aspectos da prática profissional do assistente social, bem como de outros procedimentos de investigação que podem levar à produção de conhecimento.

Na perspectiva de assegurar essa formação, reflete-se sobre a transversalidade da pesquisa no decorrer de toda formação profissional do assistente social. Indicou-se que tal transversalidade se dá através da necessária relação entre os componentes curriculares que trazem conteúdo de pesquisa e que devem viabilizar as três dimensões constitutivas do exercício profissional 
- técnico-operativa, teórico-metodológica e ético-política (SANTOS; SOUZA FILHO; BACKX, 2012). Para tal, faz-se necessário levar os discentes a apreender aspectos do movimento da realidade social, uma atividade inerente ao cotidiano dos assistentes sociais. É através da pesquisa que os discentes desenvolvem a habilidade para desvendar tal realidade, sobretudo, no que tange às expressões da questão social. É nessa direção que se defende que todas as disciplinas que compõem o curso de Serviço Social tenham uma dimensão investigativa necessária, inclusive, para elaboração de projetos interventivos.

Salienta-se que questões teóricas focadas, sobretudo, na apreensão de aspectos da realidade social presentes no cotidiano profissional, na direção política posta pelas diretrizes curriculares, potencializam e substanciam o aprendizado necessário ao exercício profissional do assistente social. Desse modo, mais que uma disciplina, a pesquisa deve ser construída como espaço de troca de experiências na perspectiva de aproximação entre a produção do conhecimento e o exercício profissional do assistente social. Para tanto, torna-se fundamental a transversalidade da pesquisa posta nessas diretrizes curriculares dos cursos de Serviço Social.

Nas reflexões sobre essa transversalidade, há, também, a tendência de situá-la como parte de um processo investigativo, que tem início nos primeiros anos do curso e que está vinculado à preparação e elaboração de Trabalhos de Conclusão de Cursos (TCC), dissertações e teses. Transversalidade é interpretada, então, como uma sequência de disciplinas voltadas à superação do senso comum e ao paulatino desenvolvimento da habilidade para pesquisar, o que deve culminar na produção de trabalhos científicos de diferentes níveis. Inclusive, a inserção de discentes em grupos de pesquisa tende a ser justificada, de forma pragmática, a partir da preparação para elaboração desses trabalhos.

Para fomentar a postura investigativa, sugere-se que os discentes sejam incentivados a participar de eventos de cunho científico (Mostras, Fóruns, Seminários, Jornadas) e de eventos da categoria profissional dos assistentes social. Concorre para tal incentivo, aproveitamento da carga horária desses eventos como equivalência para cumprimento da carga horária de Atividade 
Acadêmica Complementar; além do fomento a bolsas de iniciação científica ou até estímulos às atividades de monitoria. Contudo, destaca-se que as próprias disciplinas devem estimular a aproximação do discente com conteúdos que constituam matéria elementar da pesquisa e da dimensão investigativa da atuação profissional do assistente social.

Há também, em 15\% das UFA, segundo seus representantes, uma preocupação com relação ao desenvolvimento de pesquisas que sejam vinculadas à grande área das Ciências Sociais Aplicadas, mas em interfaces com as áreas de Ciências da Saúde e Educação, na perspectiva de articular as pesquisas de Serviço Social às demais pesquisas desenvolvidas por outros cursos da universidade. Tal preocupação inscreve-se, também, no sentido de fomento ao trabalho interdisciplinar a partir dos eixos norteadores da estrutura curricular ${ }^{8}$, privilegiando uma formação profissional ampla e pluralista dos acadêmicos, sem, contudo, distanciar-se da perspectiva ética e política que orienta os cursos de Serviço Social. Assim, os discentes são estimulados para construção do conhecimento científico desde os períodos iniciais, com as pesquisas, a princípio, bibliográficas; bem como incentivados a participar de atividades acadêmicas e elaboração de trabalhos científicos para congressos, revistas e eventos diversos realizados pelas UFA.

Em $80 \%$ das unidades de ensino, segundo seus representantes, a pesquisa se faz presente no universo estudantil desde o primeiro período, quando os discentes são apresentados no período de integração, ainda como calouros, aos projetos de pesquisa e extensão que são realizados nas respectivas instituições. Essas apresentações, geralmente, são realizadas pelos próprios discentes envolvidos na iniciação científica e projetos de extensão. É um momento, em que os calouros são instigados a identificarem-se com as temáticas que podem, inclusive, levá-los a possibilidades de desenvolver futuros projetos de pesquisas.

8 Os eixos norteadores se expressam por meio dos três núcleos de fundamentação contidos nas Diretrizes Curriculares de 1996: Núcleo de Fundamentos Teórico-Metodológicos da Vida Social; Núcleo de Fundamentos da Formação Sócio-Histórica da Sociedade Brasileira; Núcleo de Fundamentos do Trabalho Profissional. 
Estimular a atitude investigativa é entender a pesquisa como elemento constitutivo e estruturante para a formação e exercício profissional do assistente social (GUERRA, 2009), o que exige que seu conteúdo não se restrinja a uma disciplina. Nessa perspectiva, há unidades de ensino em que esse conteúdo é distribuído, ao longo do curso, sob a forma de disciplinas e oficinas sequenciais, em que são abordados diferentes aspectos da construção do conhecimento e da pesquisa. Há, ainda, a ênfase no necessário aprimoramento da articulação teoria-prática e da realização de projetos de extensão e de pesquisa a partir de demandas locais identificadas, sobretudo, nos campos de estágio. Contudo, ressalta-se que é necessário oportunizar, ao aluno de graduação, experiências de pesquisa que ultrapassem o âmbito da prática de estágio; criar formas para aproximar dois diferentes espaços: a academia, campo de produção do conhecimento, dos espaços sócio-ocupacionais, em que se materializam as ações profissionais dos assistentes sociais. Aprender a sistematizar o conhecimento sob a ótica do rigor científico não se separa da formação de um profissional, cuja competência inscreve-se no compromisso com os usuários, na perspectiva da construção do projeto ético-político do Serviço Social.

No que tange às disciplinas que tratam da pesquisa, observa-se que aquelas que se referem à elaboração de TCC, sob a forma de disciplina obrigatória, disciplina eletiva ou oficina, ganham destaque como as que tratam diretamente da temática. Porém, não deixam de ser disciplinas com turmas, independente da forma como são ofertadas, alocadas no início ou nos últimos semestres do curso.

Há, também, segundo representantes de $5 \%$ das unidades de ensino, a preocupação com a construção do projeto de pesquisa, cujo ensino se dá sob a forma de oficinas que antecedem a elaboração do TCC. Em outras unidades, a preocupação é com as modalidades e instrumentos da pesquisa que estão distribuídas entre disciplina de Método e Técnicas de Pesquisa e estatística aplicada. Existem unidades em que parte do conteúdo da pesquisa é ministrado nas disciplinas de estágio I e II, vinculadas ao exercício reflexivo sobre ao exercício profissional do assistente social. E há, ainda, unidades de ensino em que o conteúdo de 
pesquisa é organizado em núcleos ou grupos temáticos diversos ou em projetos de pesquisa e extensão. Prevalece, entretanto, nas unidades de ensino, as disciplinas denominadas "Pesquisa em Serviço Social" ou "Fundamentos da Pesquisa" e "Pesquisa Social", como disciplinas nas quais estão situados os conteúdos da ementa de pesquisa, sugeridos nas Diretrizes Curriculares de 1996. Tais disciplinas situam-se, na grade curricular, nas segundas e terceiras séries dos cursos organizados em sistema de seriado.

Salienta-se que, dada a transversalidade da pesquisa, discentes de outras disciplinas que compõem a grade curricular, utilizam instrumentos e técnicas de pesquisa, como aplicação de questionários e entrevistas, tabulação de dados, aplicação da observação sistematizada, leitura e análise de dados e aplicação das normas da Associação Brasileira de Normas Técnicas - ABNT, definição de objeto, construção textual, dentre outras. Salienta-se, também, a relação entre a pesquisa que subsidia a construção do Trabalho de Conclusão de Curso, acompanhada pelos docentes de forma individual ou em pequenos grupos. A maioria dos discentes, segundo informações de $85 \%$ dos participantes, tem como objeto de pesquisa, ainda que em construção, temáticas que advém de inquietudes e reflexões advindas dos campos de estágio.

\section{DESAFIOS À PESQUISA NAS DIRETRIZES CURRICULARES}

Os desafios da pesquisa na formação profissional, apontados no relatório de 2006 ABEPSS $^{9}$, permanecem como tendências na organização dos currículos de Serviço Social, pois entendemos que têm a ver com um movimento que extrapola a própria profissão. Considera-se aqui que o contexto de contrarreforma da educação superior e seus rebatimentos no Serviço Social infligem contradições ao processo de formação que colocam a pesquisa em xeque, em suas diferentes modalidades operacionais no currículo, seja como disciplina, seja como Atividades Acadêmicas

\footnotetext{
9 A pesquisa "Avaliação da Implementação das Diretrizes Curriculares do Curso de Serviço Social”, realizada pela ABEPSS em 2006. Seus resultados foram divulgados na revista Temporalis n.14 de 2007, particularmente os dados que tratam sobre a pesquisa na formação profissional estão entre as páginas 119 e 148.
} 
Complementares, seja por meio do desenvolvimento de grupos/ núcleos e/ou projeto de pesquisa (ABREU, 2007).

A política de educação superior em vigor é sustentada por uma larga escala de expansão universitária mercantil, que aprofunda a privatização interna das universidades públicas e amplia a privatização da educação superior presencial e a distância (DAHMER, 2008) e contribui para omitir a intensificação da desqualificação da formação profissional, sob aparência de ampliação do acesso ao "ensino" superior (LIMA, 2008).

Ressalta-se que, em termos dos desafios da pesquisa na formação, apesar da compreensão da importância da transversalidade dessa matéria na formação profissional e do conhecimento das diretrizes e da formulação de várias estratégias para implementação e operacionalização desse conteúdo durante todo o processo formativo (como ilustrado no item anterior), essas condições não vêm sendo garantidas estruturalmente para o conjunto de estudantes e docentes na maioria das UFA que participaram dos cursos da ABEPSS Itinerante.

Vários aspectos expressam a relação entre a política de educação superior mercantil de formação instrumental em curso e a precariedade das condições de realização da pesquisa no âmbito das UFA: o número excessivo de orientandos por docentes, tanto na graduação como na pós-graduação; a extensão e a pesquisa transformando-se, sem critério, em campo de estágio (SANTOS; ABREU, 2011, p. 130); os próprios assistentes sociais gestores dificultando a ida dos assistentes sociais a eventos, horários não assegurados ou insuficientes para a produção de pesquisa ou a realização de capacitação ${ }^{10}$ - o que vai contra o próprio Código de Ética profissional, que garante, em seus princípios fundamentais, o aprimoramento profissional contínuo como forma de garantia da qualidade dos serviços prestados aos usuários. Em vários relatos, apareceu a necessidade de conhecer o perfil dos usuários, mas que esse tipo de iniciativa ainda é pouco desenvolvida e/ou

10 Dados do CRESS - seccional Uberlândia -, fornecidos por um docente em um dos formulários de avaliação, mostram que mais de $90 \%$ dos assistentes sociais daquela região não constroem indicadores sociais e não possuem projeto de intervenção com base em pesquisa própria desenvolvida. 
fomentada pelas instituições prestadoras de serviços ou mesmo pelas UFA.

Ademais, foi observada uma forte competitividade entre os cursos de graduação privados para captação de alunos, normalmente levando a uma baixa possibilidade de articulação, naquela determinada região, para produção de pesquisa.

Ainda prevalece, em grande parte das unidades de ensino que oferecem cursos de Serviço Social, segundo $80 \%$ participantes do "ABEPSS-Itinerante", sobretudo entre representantes de escolas privadas, a ausência de atividades de pesquisa desenvolvidas e vinculadas a grupos/núcleos de pesquisa que envolvam alunos de graduação. Além disso, constata-se a existência de regiões sem programas de pós-graduação na área de Serviço Social, dificultando a articulação entre graduação e pós.

A realidade da pesquisa e extensão nas Instituições de Ensino Superior (IES) privadas, principalmente as de pequeno porte, restringe-se às exigências para o reconhecimento do curso, orientadas pelo Ministério da Educação (MEC), o que segundo Abreu (2007, p. 122), se expressa pela tendência à redução do ensino da pesquisa à disciplina, fortemente direcionada pelo caráter restrito da dimensão técnico-operativa.

Essa referência está condicionada pela própria concepção de pesquisa que o MEC reforça, com o apoio da Lei de Diretrizes e Bases da Educação (IAMAMOTO, 2000), alicerçada no reforço de uma concepção instrumental de formação de curto tempo, com a supressão da discussão sobre a natureza dos processos de conhecimento, da questão do método e o debate teórico-metodológico (ABREU, 2007), contrapondo- se à concepção de pesquisa presente nas Diretrizes Curriculares da ABEPSS.

A concepção do MEC de pesquisa favorece a hierarquização da produção de conhecimentos, que já vem sendo sinalizada em artigos sobre a pesquisa no Serviço Social ${ }^{11}$, com tendência de concentração das pesquisas na pós-graduação e distanciamento

11 Consultar, dentre outros, os artigos de: IAMAMOTO, 2010; BARROCO, 2010; NETTO, 2009; GUERRA, 2009; ABREU, 2007; SETUBAL, 2007; LARA, 2007; CARVALHO, 2005. 
progressivo dessas atividades das necessidades da graduação. Ao ocorrerem na graduação, realizam-se por meio de disciplinas específicas, com exceção para inserção de um baixo percentual de estudantes em iniciação científica, para posterior ingresso na pós-graduação. Com isso, perde-se a perspectiva de transversalidade proposta nas Diretrizes Curriculares de 1996.

A pesquisa como disciplina permanece sendo a modalidade prevalecente de realização nas matrizes curriculares. Além disso, a experiência de sua construção, por parte dos discentes (objetivos, métodos, justificativa, desenvolvimento, conclusões) restringe-se, segundo informações de $80 \%$ dos participantes do curso, ao Trabalho de conclusão de curso. Salienta-se, este Trabalho, de acordo com as Diretrizes Curriculares da ABEPSS de 1996:

[...] é uma exigência curricular para obtenção de diploma no curso de graduação em serviço Social. Deve ser entendido como um momento de síntese e expressão da totalidade da formação profissional. É o trabalho no qual o aluno sistematiza o conhecimento resultante de um processo investigativo, originário de uma indagação teórica, preferencialmente gerada a partir da prática do estágio no decorrer do curso. Este processo de sistematização, quando resultar de experiência de estágio, deve apresentar os elementos do trabalho profissional em seus aspectos teórico-metodológico-operativos. Realiza-se dentro de padrões e exigências metodológicas e acadêmico-científicas. Portanto, o TCC se constitui numa monografia científica elaborada sob a orientação de um professor e avaliada por banca examinadora (ABEPSS, 1996, p. 19).

Assim, esse momento de "conclusão" do curso se refere a um esforço de síntese do discente, que conjuga elementos de todo seu processo formativo, "o que traz o desafio de, no momento de elaboração da monografia, retornar a conteúdos tratados ao longo da formação, identificando possíveis lacunas e aprofundando o processo de conhecimento" (UFF, 2011, p. 2).

Esse momento de construção do TCC, considerado um momento propício para pesquisa, contudo, tem sido cada vez 
mais reduzido. Seja pelo formato que o TCC tem tomado, deixando de ser uma monografia e tornando-se artigos ou papers; seja pela forma como a orientação vem sendo conduzida em muitos cursos de Serviço Social ${ }^{12}$, com turmas de mais de 30 ou 40 estudantes com apenas um professor em sala de aula durante um semestre, ou pela não garantia de carga horária remunerada docente para orientação dos estudantes; seja pela supressão do momento de defesa do TCC, o que impede tanto o estudante como o docente de vivenciarem o rico processo de avaliação por parte de uma banca.

Todas as condições supracitadas caracterizam um processo precário de construção do trabalho de conclusão de curso, mas que, muitas vezes, é qualificado por esforço do docente que, comprometido com o projeto de formação profissional, acaba por doar muitas horas não remuneradas de trabalho além do horário contemplado nas disciplinas de TCC previstas em suas UFA, e ainda investir parte significativa de sua remuneração na aquisição de livros e, consequentemente, na cessão do seu acervo bibliográfico aos estudantes, já que as referências encontradas nas bibliotecas são insuficientes ou se resumem apenas às referências básicas do projeto pedagógico do curso.

Foi possível observar, de um lado, por parte dos docentes que participaram do ABPESS-Itinerante, sobretudo pelos que exercem suas atividades em unidades de ensino da rede privadas, o empenho na busca por qualificação em cursos de pós-graduação stricto senso, para poder, por meio da realização do mestrado ou doutorado, construir uma rotina de pesquisa na sua trajetória acadêmica, pois entendem a importância desse tipo de experiência para sua formação como assistente social e para a atuação na docência. Não há estímulo financeiro ou disponibilidade de carga horária como política institucional nas UFA privadas, e há nas instituições públicas um crescente processo de competitividade pelo aumento do financiamento por meio dos editais. Esse movimento de procura pessoal por qualificação e por estudos mais

12 Dentre os participantes, houve relatos de situações em que o professor, muitas vezes horista, é contratado para orientações coletivas. 
sistematizados também foi detectado por parte dos supervisores de campo que compuseram as turmas.

\section{CONSIDERAÇÕES FINAIS}

Os desafios que se evidenciaram durante essa experiência do "ABEPSS-Itinerante", no que tange à disciplina de pesquisa nas diretrizes curriculares de Serviço Social, sugerem a construção de uma agenda de compromissos a serem trilhados. E é na perspectiva de construí-la que se inscrevem as considerações ora apresentadas. Ou seja, mais que conclusões, pretende-se, aqui, sistematizar passos a serem trilhados.

Observa-se, tanto na experiência como facilitadoras dos módulos de pesquisa, como na coordenação do curso do ABEPSS Itinerante nas regionais, a necessária demarcação entre dois ângulos complementares, mas diversos: por um lado, a sistematização da atitude investigativa inerente ao exercício profissional que se constrói, necessariamente, a partir de leitura da realidade concreta em movimento; e, por outro lado, a consolidação do Serviço Social como área de pesquisa. Tal demarcação ressalta-se, diante da constatação de que se superou, no Serviço Social, a ilusão de que ele tem estatuto epistemológico próprio; contudo, faz-se necessário consolidá-lo como um campo de pesquisa, com o rigor teórico-metodológico que o particulariza como uma área de conhecimento, no campo das ciências sociais.

As referências às disciplinas de pesquisa ou à centralidade da pesquisa na formação profissional tratam da dimensão investigativa, no campo da instrumentalidade profissional, no mesmo compasso que a construção da pesquisa científica. São de fato, instâncias intercorrentes; mas há que se filiar a atitude investigativa à construção da pesquisa científica. Aponta-se, portanto, para a necessidade de estudos que aprofundem esta tênue, mas concreta, diferença entre dimensão investigativa e pesquisa científica.

Esses elementos, desafiam a agenda profissional do Serviço Social, a construção de pesquisas cada vez mais próximas da necessária conexão entre a processualidade analítica e as determinações objetivas das ações profissionais dos assistentes sociais. 
Observa-se que atitude investigativa pode limitar-se aos muros da empiria se tal conexão não for garantida e, em seu lugar, adensar-se na tendência tecnicista que associa a pesquisa à técnica, como se a leitura da realidade fosse desvencilhada de uma perspectiva ética e política.

Inscrever na agenda profissional a necessária viabilização da construção da pesquisa como parte do processo de formação e exercício profissional requer, entre outras ações, atividades que venham a facilitar a participação de discentes, docentes, supervisores de campo e assistentes sociais em eventos da categoria voltados a socialização de pesquisas sobre aspectos do cotidiano profissional dos assistentes sociais. A ABEPSS vem dando sinais desse tipo de espaço com o próprio curso ABEPSS Itinerante e a organização dos Grupos Temáticos de Pesquisa, embora estes últimos estejam ainda em fase embrionária de operacionalização.

Portanto, as reflexões sobre pesquisa aqui contidas visam fortalecê-la como um importante campo de resistência à lógica mercadológica de formação instrumental e como forma de estratégia de afirmação do debate plural, do pensamento crítico e de um projeto de formação profissional emancipador. NesSa direção, o fortalecimento da pesquisa na direção apontada pelas Diretrizes Curriculares inscreve, na agenda de compromissos, ações voltadas ao necessário enfrentamento da precarização do ensino e das condições adversas nas quais se realizam o trabalho docente.

\section{REFERÊNCIAS}

ABREU, Marina Maciel. Pesquisa em Serviço Social: tendências na implementação das Diretrizes Curriculares. Temporalis, ano VII, n. 14, p. 119-148, jul./dez. 2007.

ABESS/CEDEPSS - Centro de Documentação e Pesquisa em Políticas Sociais e Serviço Social . Proposta Básica para o Projeto de Formação Profissional. Revista Serviço Social e Sociedade, São Paulo: Cortez, n. 50, 1996.

ASSOCIAÇÃO BRASILEIRA DE ENSINO E PESQUISA EM SERVIÇO SOCIAL - ABEPSS. Diretrizes Gerais para o Curso de Serviço Social. 
Rio de Janeiro, nov. 1996. Disponível em: <http://www.abepss.org. br/briefing/documentos/Lei_de_Diretrizes_Curriculares_1996. pdf>. Acesso em: 25 mar. 2013.

. Diretrizes gerais para o curso de Serviço Social. Cadernos ABESS, São Paulo: Cortez, n. 7, 1997.

. Projeto "ABEPSS itinerante": as diretrizes curriculares e o projeto de formação profissional do serviço social. 2012a. Gestão 2011-2012.

. Relatório do Curso ABEPSS Itinerante da Regional Leste. 2012b. Gestão 2011-2012.

BARROCO, Maria Lucia. A dimensão ético-política do ensino e da pesquisa em Serviço Social. Temporalis, Brasília: ABEPSS, ano 10, n 19, p.161-169, jan./jun. 2010.

DAHMER, Larissa. Mercantilização do ensino superior, educação à distância e Serviço Social. Temporalis, ano VIII, n. 15, 2008.

CARVALHO, Denise Bomtempo B de C.; SILVA, Maria Ozanira Silva e (Org.). Serviço Social, Pós-Graduação e produção de conhecimento no Brasil. São Paulo: Cortez, 2005

GUERRA, Yolanda. A dimensão investigativa no exercício profissional. In: CFESS/ABEPSS. Serviço Social: direitos sociais e competências profissionais. Brasília: CFESS/ABEPSS, 2009.

IAMAMOTO, Marilda Villela. A produção teórica brasileira sobre os fundamentos do trabalho do assistente social. In: Serviço Social em tempo de capital fetiche: capital financeiro, trabalho e questão social. São Paulo: Cortez, 2010.

IAMAMOTO, Marilda V. Reforma do Ensino Superior e Serviço Social. Temporalis, Ano I, n.1, jan./jun. 2000.

LIMA, Katia. Contrarreforma da educação superior e formação profissional em Serviço Social. Temporalis, ano VIII, n. 15, 2008. 
LARA, Ricardo. Pesquisa e Serviço Social: da concepção burguesa de ciências sociais à perspectiva ontológica. Rev. Katál., Florianópolis, v. 10 n. esp. p. 73-82, 2007.

NETTO, José Paulo. Introdução ao método da teoria social. In: Serviço Social: direitos sociais e competências profissionais. Brasília: CFESS/APEPSS, 2009.

SANTOS, Claudia Monica dos; ABREU, Maria Helena Elpídeo de. Os impactos da Política Nacional de Estágio na formação profissional frente à Universidade neoliberal. Em Pauta, Rio de Janeiro, v. 9, n. 27, p. 127-142, jul. 2011.

SANTOS, Claudia Monica dos; SOUZA FILHO, Rodrigo de; BACKX, Sheila. A dimensão técnico-operativa do Serviço Social: questões para reflexão. In: SANTOS, Claudia Monica dos; BACKX, Sheila; GUERRA, Yolanda (Org.). A dimensão técnico-operativa no Serviço Social: desafios contemporâneos. Juiz de Fora: UFJF, 2012.

SETUBAL, A. A., Desafios à pesquisa no Serviço Social: da formação acadêmica à prática profissional. Rev. Katál., Florianópolis, v. 10 n. esp., p. 64-72, 2007.

SGUISSARDI, Valdemar; SILVA JUNIOR, João dos Reis. Trabalho intensificado nas Federais: pós-graduação e produtivismo acadêmico. São Paulo: Cortez, 2009.

UNIVERSIDADE FEDERAL FLUMINENSE - UFF. Normas gerais para elaboração do trabalho de conclusão de curso (TCC). 2011. Coordenação de Curso de Graduação em Serviço Social, gestão $2010-2014$. 